\title{
Effects of an Online Imagery-Based Treatment Program in Patients with Workplace-Related Posttraumatic Stress Disorder: A Pilot Study
}

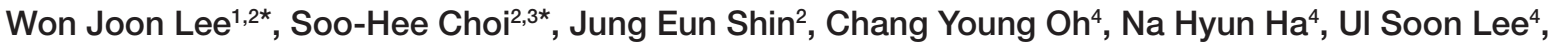 \\ Yoonji Irene $\mathrm{Lee}^{2}$, Yoobin $\mathrm{Choi}^{2}$, Saerom Lee ${ }^{5}$, Joon Hwan Jang ${ }^{6}$, Yun-Chul Hong ${ }^{7}$, and Do-Hyung Kang ${ }^{2,3 凶}$ \\ ${ }^{1}$ Department of Psychiatry, Kangdong Sacred Heart Hospital, Seoul, Republic of Korea \\ ${ }^{2}$ Department of Psychiatry, Seoul National University Hospital, Seoul, Republic of Korea \\ ${ }^{3}$ Department of Psychiatry and Institute of Human Behavioral Sciences, Seoul National University College of Medicine, Seoul, Republic of Korea \\ ${ }^{4}$ Department of Brain Education, Global Cyber University, Cheonan, Republic of Korea \\ ${ }^{5}$ Department of Occupational Health Research, Occupational Safety and Health Research Institute, Ulsan, Republic of Korea \\ ${ }^{6}$ Department of Medicine, Seoul National University, Seoul, Republic of Korea \\ ${ }^{7}$ Department of Preventive Medicine, Seoul National University Hospital, Seoul, Republic of Korea
}

Objective We developed easily accessible imagery-based treatment program for patients with post-traumatic stress disorder (PTSD) related to workplace accidents and investigated the effects of the program on various PTSD related symptoms.

Methods The program was based on an online platform and consisted of eight 15-min sessions that included script-guided imagery and supportive music. Thirty-five patients with workplace-related PTSD participated in this program 4 days per week for 4 weeks. Its effects were examined using self-report questionnaires before and after the take-home online treatment sessions.

Results After completing the 4-week treatment program, patients showed significant improvements in depressed mood ( $\mathrm{t}=3.642$, $\mathrm{p}=0.001$ ) based on the Patient Health Questionnaire-9 (PHQ-9), anxiety ( $\mathrm{t}=3.198, \mathrm{p}=0.003$ ) based on the Generalized Anxiety Disorder seven-item (GAD-7) scale, and PTSD symptoms $(\mathrm{t}=5.363, \mathrm{p}<0.001)$ based on the Posttraumatic Stress Disorder Check List (PCL). In particular, patients with adverse childhood experiences exhibited a greater degree of relief related to anxiety and PTSD symptoms than those without adverse childhood experiences.

Conclusion The present results demonstrated that the relatively short online imagery-based treatment program developed for this study had beneficial effects for patients with workplace-related PTSD.

Psychiatry Investig 2018;15(11):1071-1078

Key Words Posttraumatic stress disorder, Imagery-based treatment, Workplace injury.

\section{INTRODUCTION}

Many patients with workplace-related injuries present with symptoms of psychological distress, including anxiety, depression, anger, and physical and social impairments. ${ }^{1,2}$ Especially the reported incidence of posttraumatic stress disorder (PTSD) in injured workers is higher than the rates in individu-

Received: May 17, 2018 Revised: July 31, 2018

Accepted: September 28, 2018

$\triangle$ Correspondence: Do-Hyung Kang, MD, PhD

Department of Psychiatry, Seoul National University Hospital, 101 Daehakro, Jongno-gu, Seoul 03080, Republic of Korea

Tel: +82-2-2072-0690, Fax: +82-2-744-7241, E-mail: basuare@hanmail.net

*These authors contributed equally to this work.

(a) This is an Open Access article distributed under the terms of the Creative Commons Attribution Non-Commercial License (http://creativecommons.org/licenses/bync/4.0) which permits unrestricted non-commercial use, distribution, and reproduction in any medium, provided the original work is properly cited. als with other types of traumatic events. ${ }^{2}$ However, many patients with workplace-related PTSD cannot receive proper psychological management due to their physical disabilities and the limited compensation systems that allow only for short-term treatments of acute physical injuries. ${ }^{3}$ PTSD symptoms per se are stressful experiences for patients, ${ }^{4}$ and they can also be disruptive insofar as they increase work avoidance, ${ }^{1,5}$ which, in turn, leads to a worsening of the PTSD-related symptoms. Therefore, effective treatment of PTSD following workplace injuries is necessary to achieve successful rehabilitation and comprehensive care. However, few studies have evaluated the efficacy of treatment for patients with workplace-related PTSD. ${ }^{6}$

Although some individuals with workplace-related PTSD respond well to exposure-based therapies, ${ }^{1}$ a significant per- 
centage of patients do not improve following only this type of treatment. ${ }^{7}$ In addition, many of the standard treatments for PTSD, including cognitive behavioral therapy (CBT) and prolonged exposure, require a strong therapeutic alliance with the therapist ${ }^{6,8}$ as well as a sufficient treatment period. However, individuals with physical disabilities have a difficult time participating in these treatment modalities, and the consequent drop-out rates in this population are higher than those for other groups. ${ }^{9}$ Additionally, in most cases, patients report the absence of previous psychiatric problems and are frequently reluctant to seek psychiatric treatment due to the stigma attached to and the negative beliefs regarding mental health treatment. Therefore, the distinct characteristics of this population must be considered when developing an effective treatment program for workplace-related PTSD.

Mental imagery is a type of cognition that takes the form of perceptional experiences in the absence of direct stimuli ${ }^{10}$ and consists of mental representations of all sensory and/or perceptual images. Because imagery has a more powerful impact on emotion than the verbal processing of the same material, ${ }^{11}$ interventions using imagery are suggested as effective tools for the relief of emotional distress, including the symptoms associated with PTSD. ${ }^{12}$ According to the cognitive model of PTSD described by Ehlers and Clark, ${ }^{13}$ PTSD becomes persistent when traumatic information is processed in a way that leads to the sensing of a serious current threat. Therefore, one of the main therapeutic targets of this model involves updating the traumatic memory during cognitive therapy. It has been suggested that directly addressing the use of imagery can be a powerful tool for the modification of traumatic memories because cognitive-affective disturbances in trauma-related memories are embedded in the traumatic image themselves. ${ }^{14}$ Guided imagery is a form of imagery based cognitive-behavioral techniques that produce therapeutic changes through mind-body interactions by directing individuals to create and manipulate specific mental images guided by script-based verbal instructions.

One study found that victims of industrial accidents with PTSD who failed to show improvements following prolonged exposure therapy responded to imagery based therapy. ${ }^{6}$ Thus, the present study developed a trauma-focused and imagerybased take-home treatment program using guided imagery techniques that were based on the results achieved by variety of imagery-focused approaches. Additionally, this program borrowed techniques from various forms of mind-body training, such as breathing relaxation, muscle relaxation, and meditation, under the assumption that these tools would not only have their own therapeutic effects but would also enhance attention and concentration and enhance the effectiveness of attempts to modulate imagery..$^{15}$ Thus, the present study aimed to investigate the effectiveness of an online imagery-based program for treating the psychiatric symptoms of patients with PTSD related to workplace accidents.

\section{METHODS}

\section{Participants}

The present study included 35 patients who were diagnosed with PTSD following workplace accidents by one psychiatrist based on DSM-IV criteria. The participants were recruited from Seoul National University Hospital and the Complex Regional Pain Syndrome Association in Korea. All patients were between 20 and 65 years of age and were willing to participate in the study. Patients with a cognitive disability or psychiatric symptoms that might have interfered with understanding the questionnaires were excluded from the study. The protocol was approved by the Institutional Review Board at the Seoul National University Hospital (approval number: H-1605-033-760), all participants provided written consent, and the study was conducted in accordance with the guidelines of the Declaration of Helsinki.

\section{The online imagery-based treatment program}

The program consisted of four phases that included eight sessions (Table 1); this process was repeated twice over 4 weeks. The first phase was an introductory stage that helped the patients become more aware of their feelings and sensory experiences. During this phase, the participants performed body relaxation exercises and mind training that developed their ability to more vividly experience their sensory responses to imagery. The second phase was designed to mediate any trauma that occurred in early life by engaging in exercises involving meditation and breathing. This phase was comprised of three substages: releasing negative memories, bringing up positive feelings, and learning emotional regulation. The third major trauma mediation phase was developed to address traumas that were formed relatively recently and also consisted of three substages: memory-conversion meditation to change negative memories into positive memories, memory-purge meditation to eliminate the negative memories, and facing the self, which involved comforting oneself by communicating with the inner-self. The aim of the fourth and final phase was to restore a positive belief in oneself following relaxation, breathing, and self-recovering meditations that aimed to establish positive self-values.

The participants individually completed the take-home online program 4 days per week over 4 weeks. During the 4 weeks of study period, there were no change in the drug prescription. Two weeks after the study enrollment, the participants were contacted by phone call and encouraged to listen to the program. 
WJ Lee et al.

Table 1. Contents of the imagery-based program

\begin{tabular}{|c|c|c|c|}
\hline Stage & & Purpose & Contents \\
\hline Introductory stage & 1 & Observing self & $\begin{array}{l}\text { - Relaxation exercise } \\
\text { - Imagery training using the senses of touch, smell, sound, sight and taste }\end{array}$ \\
\hline \multirow[t]{3}{*}{$\begin{array}{l}\text { Meditation for } \\
\text { early life trauma }\end{array}$} & 2 & Releasing negative memories & $\begin{array}{l}\text { - Relaxation exercise } \\
\text { - Relaxation meditation } \\
\text { - Release breathing meditation }\end{array}$ \\
\hline & 3 & Bringing up positive feelings & $\begin{array}{l}\text { - Chest breathing } \\
\text { - Self-healing meditation }\end{array}$ \\
\hline & 4 & Learning emotional regulation & $\begin{array}{l}\text { - Relaxation exercise } \\
\text { - Amygdala-refreshing meditation } \\
\text { - Brain-refreshing meditation }\end{array}$ \\
\hline \multirow[t]{3}{*}{$\begin{array}{l}\text { Meditation for } \\
\text { major trauma }\end{array}$} & 5 & $\begin{array}{l}\text { Recovering from traumatic } \\
\text { experience I }\end{array}$ & $\begin{array}{l}\text { - Brain wave vibration meditation } \\
\text { - Relaxation meditation } \\
\text { - Memory-conversion meditation }\end{array}$ \\
\hline & 6 & $\begin{array}{l}\text { Recovering from traumatic } \\
\text { experience II }\end{array}$ & $\begin{array}{l}\text { - Brain wave vibration meditation } \\
\text { - Relaxation meditation } \\
\text { - Memory-purge meditation }\end{array}$ \\
\hline & 7 & Confronting self & $\begin{array}{l}\text { - Brain wave vibration meditation } \\
\text { - Relaxation meditation } \\
\text { - Self-comforting meditation }\end{array}$ \\
\hline Finishing stage & 8 & Recovering self & $\begin{array}{l}\text { - Relaxation exercise } \\
\text { - Chest breathing } \\
\text { - Self-recovering meditation }\end{array}$ \\
\hline
\end{tabular}

Each daily session, which lasted 15 min, consisted of auditory guidance and background music; appropriate soundenhanced imagery experiences aided relaxation and increased the emotional impact of each treatment session. ${ }^{16}$ The type of sound was selected based on the goal that the guided imagery was intended to achieve. The program was developed by psychiatrists at Seoul National University Hospital in conjunction with brain education experts at Global Cyber University. While other treatments for PTSD that are based on guided imagery techniques do not directly utilize imagined exposure to the trauma, ${ }^{17,18}$ the present program was developed with a focus on childhood trauma and the current trauma image.

\section{Psychiatric measures}

To evaluate the baseline features of the study participants, a trained psychiatrist assessed the type of industrial accident, diagnosis and duration of PTSD, and comorbid psychiatric symptoms of each participant.

The Adverse Childhood Experiences (ACE) questionnaire was administrated to assess previous traumatic events. ${ }^{19}$ This questionnaire was developed to assess the correlation between adverse childhood experiences and the health-risk behaviors of respondents. It contains 10 questions divided into three subscales: abuse (physical, emotional, and sexual), neglect (physical and emotional), and dysfunctional family experiences. In the present study Cronbach's alpha of the ACE was 0.696. Additionally, feelings of guilt associated with work-related traumatic events were measured with the Trauma-Related Guilt Inventory (TRGI) developed by Kubany et al. ${ }^{20}$ The questions on the TRGI are categorized into four subscales: wrongdoing, hindsight-bias/responsibility, distress, and lack of justification. Higher TRGI scores represent a strong possibility of feeling guilt associated with traumatic events. For the present study, 14 of 32 questionnaires included the TRGI. In the present study Cronbach's alpha of the TRGI was 0.650.

To investigate the effects of the online program, several selfreport questionnaires were completed prior to and after the program. The Patient Health Questionnaire-9 (PHQ-9) consists of nine depression modules based on the Diagnostic and Statistical Manual of Mental Disorders, Fourth Edition (DSM-IV). ${ }^{21} \mathrm{~A}$ four-point Likert-type scale ranging from 0 (not at all) to 3 (nearly every day) is used to score each question, and the total PHQ-9 score is used to identify mild (5-9), moderate (10-14), moderately severe (15-19), and severe $(\geq 20)$ depression. In the present study Cronbach's alpha of the PHQ9 was 0.844 .

The Generalized Anxiety Disorder seven-item scale (GAD7) measures the anxiety status of patients during the previous 2 weeks. ${ }^{22}$ Each question is scored with a Likert-type scale 
ranging from 0 (not at all) to 3 (several days), and GAD-7 total scores of 5,10 , and 15 represent mild, moderate, and severe anxiety, respectively. In the present study Cronbach's alpha of the GAD was 0.893 .

The PTSD Check List (PCL) assesses the development of PTSD in respondents after exposure to a traumatic event. ${ }^{23}$ The PCL is comprised of 17 items that assess re-experiencing, avoidance, and hyperarousal; higher PCL scores indicate the possibility that respondents experienced distressing events and were suffering from PTSD. The Cronbach's alpha in the current study was 0.917 for the full scale. The Cronbach's alpha for the three subscales ranged between 0.809 and 0.899: re-experiencing (0.839), avoidance (0.809), hyperarousal (0.899).

The Posttraumatic Growth Inventory (PTGI) was developed to evaluate positive changes that occur after respondents are exposed to traumatic events. ${ }^{24}$ In the present study, a short form of the PTGI was used; this form consists of 10 items that evaluate positive changes using subscales addressing topics such as new possibilities, personal strength, spiritual change, appreciation of life, and relating to others. In the present study Cronbach's alpha of the PTGI was 0.887.

The Functional Social Support Questionnaire (FSSQ) assesses the strength of respondents' social support network. ${ }^{25}$ For the present study, 13 items scored on a five-point Likerttype scale were included to evaluate quantity of support, instrumental support, confidence, and affective support. In the present study Cronbach's alpha of the FSSQ was 0.944.

Finally, the P4 Suicidality Screener is a brief measurement of suicidal ideation, which is commonly comorbid with depression. ${ }^{26}$ This measure consists of four items that assess past suicide attempts, suicide plans, probability of completing suicide, and preventive factors. Based on the rating, the respondents can be classified into one of three groups according to whether they were at minimal, lower, or higher risk.

\section{Statistical analysis}

All statistical analyses were carried out using SPSS 24.0. Paired t-tests and Wilcoxon signed-rank tests were used to compare the questionnaire results before and after the 4-week program. A history of childhood traumatic events is a strong risk factor for the development and maintenance of PTSD. Thus, the present study also included a subgroup comparison analysis using the ACE scale; independent t-tests and chisquare tests were used to examine differences among the subgroups. P-values $<0.05$ were considered to indicate statistical significance.

\section{RESULTS}

Of 54 patients aged 20 to 65 years with work-related PTSD during the study period (June 2016 to September 2016), 35 were allocated to clinical trial and treated accordingly. Of the 19 subjects excluded from the study, 6 were excluded due to cognitive problems, and 13 refused to participate in the study. Four weeks later, all participants reported that they had completed at least two program listening sessions.

Table 2 presents the demographic and clinical characteristics of the study participants. Most participants were male with comorbid psychiatric symptoms, showed a chronic course of PTSD, and reported moderate levels of trauma-related guilt feelings. Additionally, $60 \%$ of the population $(n=21)$ reported adverse childhood experiences. After 4 weeks of treatment, participants demonstrated significant improvements in terms of depression, anxiety, and PTSD symptoms (Table 3). How-

Table 2. Demographic and clinical characteristics of the participants

\begin{tabular}{|c|c|c|}
\hline Variable & Mean & $\mathrm{SD}$ \\
\hline Age & 48.1 & 8.2 \\
\hline Duration of posttraumatic stress disorder & 60.1 & 48.5 \\
\hline Trauma-Related Guilt Inventory, total & 37.7 & 3.7 \\
\hline Distress factor & 14.3 & 1.3 \\
\hline Wrongdoing & 5.8 & 3.2 \\
\hline Hindsight-bias/responsibility & 9.5 & 2.2 \\
\hline \multirow[t]{2}{*}{ Lack of justification } & 8.1 & 2.1 \\
\hline & $\mathrm{N}$ & $\%$ \\
\hline Sex, male & 30 & 85.7 \\
\hline \multicolumn{3}{|l|}{ Types of industrial accidents } \\
\hline Falling & 19 & 54.3 \\
\hline Hit by the object & 4 & 11.4 \\
\hline Tripped/cut off or stabbed & 3 & 8.6 \\
\hline Assaulted or bumped & 2 & 5.7 \\
\hline Fire & 1 & 2.9 \\
\hline \multicolumn{3}{|l|}{ Comorbid psychiatric symptoms, yes } \\
\hline Depression & 25 & 71.4 \\
\hline Post-concussion syndrome & 2 & 5.7 \\
\hline Pain & 33 & 94.2 \\
\hline Adverse Childhood Experiences, yes & 21 & 60.0 \\
\hline Abuse & 11 & 31.4 \\
\hline Neglect & 10 & 28.6 \\
\hline Dysfunctional family & 12 & 34.4 \\
\hline \multicolumn{3}{|l|}{ Medications, yes } \\
\hline Antidepressants & 19 & 54.3 \\
\hline Antipsychotics & 21 & 60.0 \\
\hline Anticonvulsants & 20 & 57.1 \\
\hline Anxiolytics & 22 & 62.9 \\
\hline Opioids & 15 & 42.9 \\
\hline
\end{tabular}


ever, there were no changes in posttraumatic growth, functional social support, or suicidality.

The subgroup analysis revealed that participants with adverse childhood experiences showed greater symptom relief, measured by scores on the GAD-7 $(\mathrm{t}=-2.142, \mathrm{p}=0.040)$ and PCL ( $t=-3.214, p=0.003)$, compared to those without adverse childhood experiences (Figure 1). In terms of the PCL subscores, the groups significantly differed on avoidance $(t=$

Table 3. Psychiatric measures pre and post of four weeks of online imagery-based treatment program

\begin{tabular}{|c|c|c|c|c|c|c|}
\hline \multirow{2}{*}{ Variable } & \multicolumn{2}{|c|}{ Pre } & \multicolumn{2}{|c|}{ Post } & \multirow{2}{*}{$\mathrm{t}$} & \multirow{2}{*}{$\mathrm{p}$} \\
\hline & Mean & $\mathrm{SD}$ & Mean & SD & & \\
\hline Patient Health Questionnaire & 21.0 & 4.6 & 18.0 & 6.4 & 3.642 & 0.001 \\
\hline Generalized Anxiety Disorder 7-item scale & 16.4 & 4.3 & 13.8 & 5.6 & 3.198 & 0.003 \\
\hline Post-Traumatic Stress Disorder Check List, total & 52.2 & 10.6 & 42.0 & 16.0 & 5.363 & $<0.001$ \\
\hline Re-experiencing & 14.7 & 3.6 & 12.0 & 5.0 & 4.721 & $<0.001$ \\
\hline Avoidance & 20.9 & 5.0 & 17.1 & 5.1 & 4.199 & $<0.001$ \\
\hline Hyperarousal & 16.5 & 3.5 & 13.0 & 4.9 & 5.054 & $<0.001$ \\
\hline Posttraumatic Growth Inventory, total & 17.3 & 11.4 & 18.9 & 13.2 & 0.699 & 0.49 \\
\hline Relating to others & 2.5 & 2.8 & 3.6 & 3.1 & 1.378 & 0.17 \\
\hline New possibilities & 2.9 & 2.9 & 3.4 & 3.0 & 0.833 & 0.41 \\
\hline Personal strength & 2.8 & 2.8 & 3.8 & 2.8 & 1.671 & 0.10 \\
\hline Spiritual change & 3.2 & 3.0 & 3.0 & 3.2 & 0.070 & 0.94 \\
\hline Appreciation of life & 5.9 & 2.8 & 5.1 & 3.0 & 1.695 & 0.10 \\
\hline \multirow[t]{2}{*}{ Functional Social Support Questionnaire } & 2.2 & 1.0 & 2.2 & 1.0 & 0.197 & 0.84 \\
\hline & $\mathrm{N}$ & $\%$ & $\mathrm{~N}$ & $\%$ & $\mathrm{Z}$ & $\mathrm{p}$ \\
\hline P4 suicidality screener & & & & & 0.576 & 0.57 \\
\hline High & 29 & 82.9 & 29 & 82.9 & & \\
\hline Low & 4 & 11.4 & 5 & 2.9 & & \\
\hline Minimal & 2 & 5.7 & 1 & 14.3 & & \\
\hline
\end{tabular}

SD: standard deviation

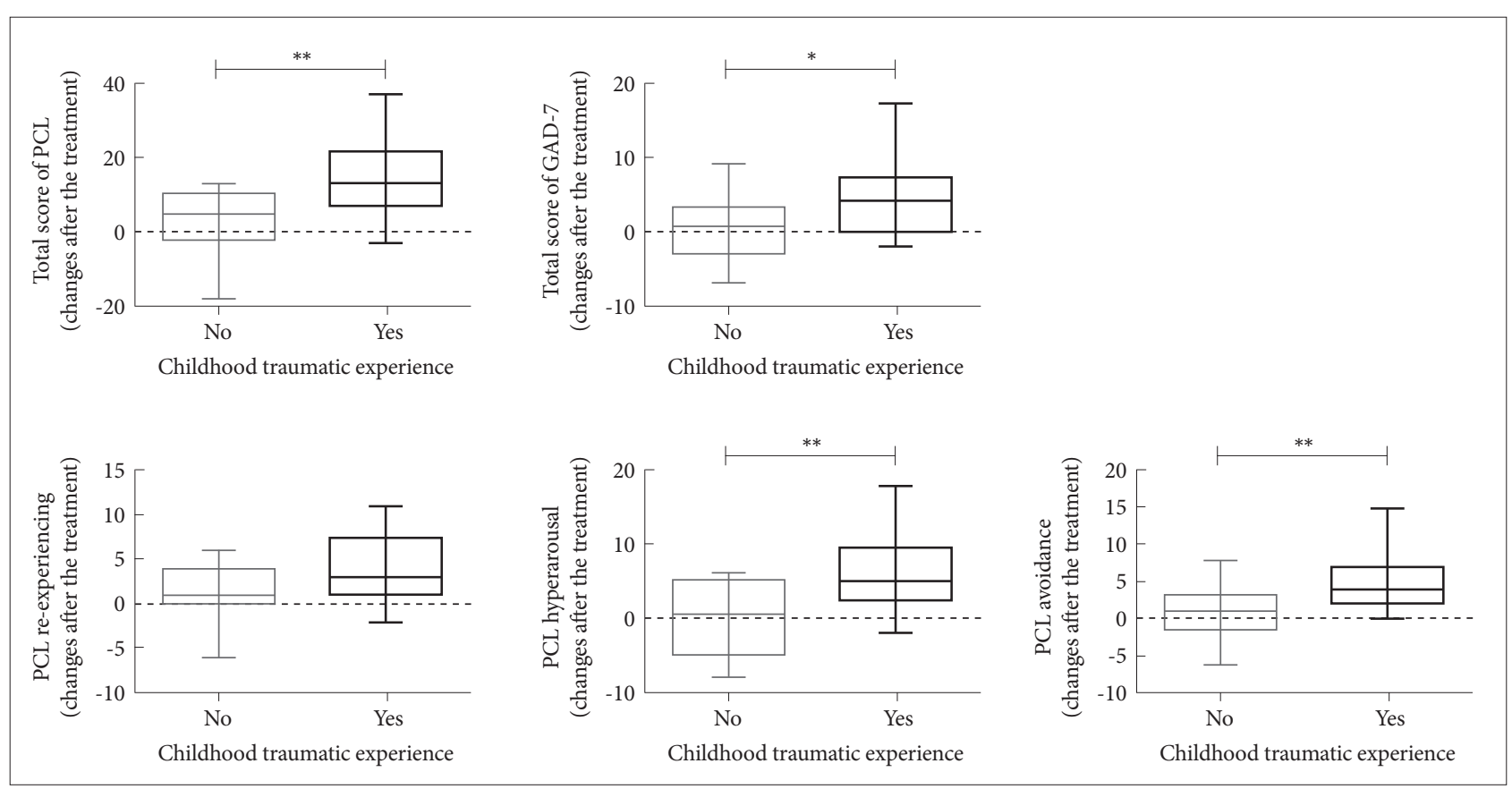

Figure 1. Differences of the effects of online imagery-based treatment program according to the presence of childhood traumatic experience. ${ }^{*} p<0.05,{ }^{* *} p<0.01$. PCL: PTSD Check List, GAD-7: Generalized Anxiety Disorder seven-item scale. 
-2.951, $\mathrm{p}=0.006)$ and hyperarousal $(\mathrm{t}=-2.997, \mathrm{p}=0.005)$. There were no other significant differences between the groups, including with regard to demographic and clinical characteristics.

\section{DISCUSSION}

The main purpose of the present study was to determine the therapeutic effects of an online-based treatment program for patients with work-related injuries that focused on the modulation of imagery. Although online-based methods can effectively treat psychological issues in and provide stress management for healthy participants and workers, ${ }^{27,28}$ no studies have investigated these variables in patients with workplace-related PTSD. Because the present program is based on an online platform, patients with reduced mobility can receive treatment at home. Therefore, this type of self-help intervention provides the opportunity for individuals to enhance their sense of control and mastery, which are thought to be lost in most patients with PTSD. Additionally, this treatment program is highly structured and does not require a high degree of expertise by the therapist or the inclusion of many resources, which makes this therapy affordable.

Even with a short treatment period of 4 weeks, the participants exhibited significant improvements in depression, anxiety, and PTSD symptoms. The pre-post effect size for PTSD symptoms on the PCL was reflected in a Cohen's $d$ value of 0.906, which is smaller than those for other CBT-based therapies for PTSD $(\mathrm{d}=1.5)^{29}$ and similar to $(\mathrm{d}=0.85)^{18}$ or lower than $(\mathrm{d}=1.43)^{17}$ the rates reported for other guided imagery therapies for PTSD. These differences were likely to due to the fact that a large portion of the present sample was experiencing chronic pain. PTSD patients with chronic pain or physical injury experience higher levels of distress ${ }^{30,31}$ and show poorer outcomes after treatment. ${ }^{32,33}$

Overall, the dimensions that reflected responses to the present treatment program were mainly related to emotion, and these changes were attributed to the strong impact of imagery on emotional regulation. ${ }^{11}$ In this program, imaginary exposure to the traumatic memory is not processed through habituation, as is the case with exposure-based therapy. Instead, the traumatic memory is either faded or erased via one's imagination or substituted by pleasurable imagery. Erasing negative images can effectively decrease arousal that is associated with negative memories, whereas imagining pleasurable images can induce positive emotions. Regulating emotions with imagery-based treatments can change beliefs that the disturbing images cannot be completely controlled; at the same time, their promotion of alternatives in the form of images rather than verbal representations may render patients more likely to act on these changes. ${ }^{34}$ These changes in the mean- ing of the self may allow for the development of more positive beliefs about the self.

From a clinical perspective, individuals who are exposed to childhood trauma tend to develop PTSD more often ${ }^{35}$ and are more likely to be exposed to traumatic events in adulthood than those who did not experience childhood trauma. ${ }^{36,37}$ However, PTSD patients with childhood trauma could be considered a distinct group based on their epigenetically-induced altered neurobiological state ${ }^{38}$ and complex symptomatology, ${ }^{39}$ which differs from those of individuals without a history of childhood trauma. As a result, it has been suggested that PTSD patients with childhood trauma require personalized therapy. However, the effects of childhood trauma on the treatment outcomes of PTSD patients who receive CBT remain uncertain. ${ }^{40}$ In cases of depression, existence of the childhood trauma influences treatment outcomes, ${ }^{41}$ psychotherapy is suggested to be more effective than pharmacotherapy for treating depressive patients with childhood trauma. ${ }^{42}$ Thus, the present treatment program may be an effective treatment modality for PTSD patients with childhood trauma.

There were no significant differences in the demographic or clinical profiles of the present participants according to the presence or absence of childhood trauma. However, there are two reasons that this treatment program may be more effective in patients with childhood trauma. First, the imagery content that this treatment utilizes includes both current and childhood traumas. The manner in which childhood trauma affects psychological states in adulthood is indirectly mediated by factors such as low self-esteem and insecure attachment. However, if childhood trauma directly influences responses to a current trauma, then interventions for the childhood trauma, such as the present program, may have an effect on the reaction to the current trauma. Second, it appears that differences in imaginative suggestibility are reflected in responses to imagery-based treatments. ${ }^{43}$ According to studies investigating the relationship between imaginative suggestibility and childhood trauma, individuals who experience trauma during childhood may develop skills related to imaginative involvement. ${ }^{44}$ Therefore, the present results showing a greater responsiveness in the group with childhood trauma may reflect their higher degree of imaginative suggestibility.

Meanwhile, there were no significant effects of the program on posttraumatic growth, perceived social support, or suicidality. Although few studies have investigated the effects of PTSD treatment on suicidality, two reported diminished levels of suicidal ideation after evidence-based treatments. ${ }^{45,46}$ However, the subjects in those studies consisted primarily of employed female civilians, which is quite different from the present study sample, which was composed primarily of unemployed male subjects. Improvements in PTSD symptoms 
are related to improvements in suicidality when depressive symptoms are accounted for ${ }^{46}$ Similarly, studies investigating the temporal association between suicidality and PTSD symptoms reported that the effect size for suicidality was low and that improvements in PTSD symptoms were followed by diminished suicidality. ${ }^{47}$ Therefore, it will be necessary to confirm whether improvements in suicidality can be achieved after a sufficient period of time has passed.

In the case of posttraumatic growth as assessed using the PTGI, there were slight improvements in the dimensions assessing relating to others, new possibilities, and personal strength; however, these changes were not statistically significant. A study using the PTGI to assess the effects of PTSD treatment found significant improvements in these dimensions and showed that the pretreatment PTGI score influenced the treatment outcome. ${ }^{48}$ The nonsignificant effect of PTGI score in the present study may have been due to the fact that the baseline PTGI scores in the present sample were approximately half the values of those in the previous study sample. Although the role that social support plays in the development of PTSD is well documented, the relationship between the course of PTSD and social support requires further investigation. Consistent with the interpersonal difficulties that accompany PTSD symptoms, some evidence indicates that perceived social support can be influenced by PTSD symptom severity. ${ }^{49}$ However, due to the social damages experienced by PTSD patients during the long duration of their illness (an average of 5 years), a 4-week treatment period may be too brief to observe changes in the social support system of an individual..$^{50}$ Otherwise, this lack of any change could imply that there were not sufficient resources to support the patients. ${ }^{51}$

One of weakness of the present study was that the design lacked a control group; thus, it was not possible to rule out that the therapeutic improvements resulted from a natural course or other therapeutic interventions, such medication, during the study. Additionally, this study did not collect follow-up data, which would be necessary to evaluate any additional therapeutic effects related to suicidality, posttraumatic growth, and perceived social support that were not observed in the present 4-week study period as well as to determine if the observed effects were maintained over the long term.

In conclusion, the present study showed that a short 4-week take-home imagery-based treatment program was effective for patients with workplace-related PTSD. Because PTSD is difficult to treat in its chronic stages, the application of early interventions is important from a therapeutic perspective. Therefore, due to the easy accessibility of this online program, it could be used as an effective early intervention for individuals with workplace injuries.

\section{Acknowledgments}

This work was supported by the Occupational Safety and Health Research Institute, (2016-research institute-753).

\section{REFERENCES}

1. Grunert BK, Matloub HS, Sanger JR, Yousif NJ. Treatment of posttraumatic stress disorder after work-related hand trauma. J Hand Surg Am 1990;15:511-515.

2. Ghisi M, Novara C, Buodo G, Kimble MO, Scozzari S, Di Natale A, et al. Psychological distress and post-traumatic symptoms following occupational accidents. Behav Sci (Basel) 2013;3:587-600.

3. MacDonald HA, Colotla V, Flamer S, Karlinsky H. Posttraumatic stress disorder (PTSD) in the workplace: a descriptive study of workers experiencing PTSD resulting from work injury. J Occup Rehabil 2003;13:63-77.

4. Colotla VA, Bowman ML, Shercliffe RJ. Test-retest stability of injured workers' MMPI-2 profiles. Psychol Assess 2001;13:572-576.

5. Matthews LR. Posttrauma employability of people with symptoms of PTSD and the contribution of work environments. Int J Disabil Manag 2006;1:87-96.

6. Grunert BK, Weis JM, Smucker MR, Christianson HF. Imagery rescripting and reprocessing therapy after failed prolonged exposure for post-traumatic stress disorder following industrial injury. J Behav Ther Exp Psychiatry 2007;38:317-328.

7. Grunert BK, Devine CA, Matloub HS, Sanger JR, Yousif NJ, Anderson $\mathrm{RC}$, et al. Psychological adjustment following work-related hand injury: 18-month follow-up. Ann Plast Surg 1992;29:537-542.

8. Hembree EA, Rauch SA, Foa EB. Beyond the manual: The insider's guide to prolonged exposure therapy for PTSD. Cogn Behavl Pract 2003;10:22-30.

9. Gros DF, Allan NP, Lancaster CL, Szafranski DD, Acierno R. Predictors of treatment discontinuation during prolonged exposure for PTSD. Behav Cogn Psychother 2018;46:35-49.

10. Kosslyn SM, Thompson WL, Ganis G. The Case for Mental Imagery. New York: Oxford University Press; 2006.

11. Holmes EA, Mathews A. Mental imagery and emotion: a special relationship? Emotion 2005;5:489-497.

12. Holmes EA, Arntz A, Smucker MR. Imagery rescripting in cognitive behaviour therapy: images, treatment techniques and outcomes. J Behav Ther Exp Psychiatry 2007;38:297-305.

13. Ehlers A, Clark DM. A cognitive model of posttraumatic stress disorder. Behav Res Ther 2000;38:319-345.

14. Smucker MR. Post-Traumatic Stress Disorder. In: Leahy RL, Editor. Practicing Cognitive Therapy: A Guide to Interventions. Northvale, NJ: Jason Aronson, 1997, p.193-220.

15. Leuner H. Guided affective imagery: an account of its development. J Ment Imag 1977;1:73-91.

16. McKinney CH. The effect of music on imagery. J Music Ther 1990; 27:34-46.

17. Strauss J, Calhoun P, Marx C. Guided Imagery as a Therapeutic Tool in Post Traumatic Stress Disorder. In: LeDoux J, Keane T, Shiromani P, Editors. Post-Traumatic Stress Disorder. Towota, NJ: Humana Press, 2009, p.363-373.

18. Jain S, McMahon GF, Hasen P, Kozub MP, Porter V, King R, et al. Healing Touch with Guided Imagery for PTSD in returning active duty military: a randomized controlled trial. Mil Med 2012;177:10151021.

19. Felitti VJ, Anda RF, Nordenberg D, Williamson DF, Spitz AM, Edwards V, et al. Relationship of childhood abuse and household dysfunction to many of the leading causes of death in adults. The Adverse Childhood Experiences (ACE) Study. Am J Prev Med 1998;14:245258.

20. Kubany ES, Haynes SN, Abueg FR, Manke FP, Brennan JM, Stahura C. Development and validation of the Trauma-Related Guilt Inventory 
(TRGI). Psychol Assess 1996;8:428.

21. Kroenke K, Spitzer RL, Williams JB. The PHQ-9: validity of a brief depression severity measure. J Gen Intern Med 2001;16:606-613.

22. Spitzer RL, Kroenke K, Williams JB, Löwe B. A brief measure for assessing generalized anxiety disorder: the GAD-7. Arch Intern Med 2006;166:1092-1097.

23. Weathers FW, Litz BT, Herman DS, Huska JA, Keane TM. The PTSD Checklist (PCL): Reliability, validity, and diagnostic utility. annual convention of the international society for traumatic stress studies, San Antonio, TX: International Society of Traumatic Stress Studies, October 1993.

24. Cann A, Calhoun LG, Tedeschi RG, Taku K, Vishnevsky T, Triplett $\mathrm{KN}$, et al. A short form of the Posttraumatic Growth Inventory. Anxiety Stress Coping 2010;23:127-137.

25. Broadhead WE, Gehlbach SH, de Gruy FV, Kaplan BH. The DukeUNC Functional Social Support Questionnaire. Measurement of social support in family medicine patients. Med Care 1988;26:709-723.

26. Dube P, Kurt K, Bair MJ, Theobald D, Williams LS. The p4 screener: evaluation of a brief measure for assessing potential suicide risk in 2 randomized effectiveness trials of primary care and oncology patients. Prim Care Companion J Clin Psychiatry 2010;12.

27. Ebert DD, Lehr D, Heber E, Riper H, Cuijpers P, Berking M. Internetand mobile-based stress management for employees with adherencefocused guidance: efficacy and mechanism of change. Scand J Work Environ Health 2016;42:382-394.

28. Jung YH, Ha TM, Oh CY, Lee US, Jang JH, Kim J, et al. The effects of an online mind-body training program on stress, coping strategies, emotional intelligence, resilience and psychological state. PLoS One 2016;11:e0159841.

29. Bradley R, Greene J, Russ E, Dutra L, Westen D. A multidimensional meta-analysis of psychotherapy for PTSD. Am J Psychiatry 2005;162: 214-227.

30. Otis JD, Keane TM, Kerns RD. An examination of the relationship between chronic pain and post-traumatic stress disorder. J Rehabil Res Dev 2003;40:397-405.

31. Otis JD, Keane TM, Kerns RD, Monson C, Scioli E. The development of an integrated treatment for veterans with comorbid chronic pain and posttraumatic stress disorder. Pain Med 2009;10:1300-1311.

32. Gillespie K, Duffy M, Hackmann A, Clark DM. Community based cognitive therapy in the treatment of posttraumatic stress disorder following the Omagh bomb. Behav Res Ther 2002;40:345-357.

33. Taylor S, Fedoroff IC, Koch WJ, Thordarson DS, Fecteau G, Nicki RM. Posttraumatic stress disorder arising after road traffic collisions: patterns of response to cognitive-behavior therapy. J Consult Clin Psychol 2001;69:541-551.

34. Holmes EA, Mathews A. Mental imagery in emotion and emotional disorders. Clin Psychol Rev 2010;30:349-362.

35. Bremner JD, Southwick SM, Johnson DR, Yehuda R, Charney DS. Childhood physical abuse and combat-related posttraumatic stress disorder in Vietnam veterans. Am J Psychiatry 1993;150:235-239.
36. Brewin CR, Andrews B, Valentine JD. Meta-analysis of risk factors for posttraumatic stress disorder in trauma-exposed adults. J Consult Clin Psychol 2000;68:748-766.

37. Widom CS. Posttraumatic stress disorder in abused and neglected children grown up. Am J Psychiatry 1999;156:1223-1229.

38. Mehta D, Klengel T, Conneely KN, Smith AK, Altmann A, Pace TW, et al. Childhood maltreatment is associated with distinct genomic and epigenetic profiles in posttraumatic stress disorder. Proc Natl Acad Sci U S A 2013;110:8302-8307.

39. Cloitre M, Stolbach BC, Herman JL, van der Kolk B, Pynoos R, Wang J, et al. A developmental approach to complex PTSD: childhood and adult cumulative trauma as predictors of symptom complexity. J Trauma Stress 2009;22:399-408.

40. Ford JD, Kidd P. Early childhood trauma and disorders of extreme stress as predictors of treatment outcome with chronic posttraumatic stress disorder. J Trauma Stress 1998;11:743-761.

41. Nanni V, Uher R, Danese A. Childhood maltreatment predicts unfavorable course of illness and treatment outcome in depression: a metaanalysis. Am J Psychiatry 2012;169:141-151.

42. Craighead WE, Nemeroff CB. The impact of early trauma on response to psychotherapy. Clin Neurosci Res 2005;4:405-411.

43. Kwekkeboom KL, Wanta B, Bumpus M. Individual difference variables and the effects of progressive muscle relaxation and analgesic imagery interventions on cancer pain. J Pain Symptom Manage 2008; 36:604-615

44. Bryant RA. Fantasy proneness, reported childhood abuse, and the relevance of reported abuse onset. Int J Clin Exp Hypn 1995;43:184-193.

45. Harned MS, Korslund KE, Linehan MM. A pilot randomized controlled trial of Dialectical Behavior Therapy with and without the Dialectical Behavior Therapy Prolonged Exposure protocol for suicidal and self-injuring women with borderline personality disorder and PTSD. Behav Res Ther 2014;55:7-17.

46. Gradus JL, Suvak MK, Wisco BE, Marx BP, Resick PA. Treatment of posttraumatic stress disorder reduces suicidal ideation. Depress Anxiety 2013;30:1046-1053.

47. Cox KS, Mouilso ER, Venners MR, Defever ME, Duvivier L, Rauch SAM, et al. Reducing suicidal ideation through evidence-based treatment for posttraumatic stress disorder. J Psychiatr Res 2016;80:59-63.

48. Hagenaars MA, van Minnen A. Posttraumatic growth in exposure therapy for PTSD. J Trauma Stress 2010;23:504-508.

49. King DW, Taft C, King LA, Hammond C, Stone ER. Directionality of the association between social support and Posttraumatic Stress Disorder: a longitudinal investigation 1. J Appl Soc Psychol 2006;36:29802992.

50. Laffaye C, Cavella S, Drescher K, Rosen C. Relationships among PTSD symptoms, social support, and support source in veterans with chronic PTSD. J Trauma Stress 2008;21:394-401.

51. Hansen NB, Eriksen SB, Elklit A. Effects of an intervention program for female victims of intimate partner violence on psychological symptoms and perceived social support. Eur J Psychotraumatol 2014;5. 